\title{
Comparative impact of hospital-acquired infections on medical costs, length of hospital stay and outcome between community hospitals and medical centres
}

\author{
W.H. Sheng ${ }^{a}$, J.T. Wang ${ }^{b}$, D.C.T. Lu', W.C. Chie ${ }^{\text {d }}$, Y.C. Chen ${ }^{a}$, \\ S.C. Chang ${ }^{a, *}$
}

${ }^{a}$ Department of Internal Medicine, National Taiwan University Hospital, Taipei City, Taiwan, ROC

${ }^{b}$ Department of Internal Medicine, Far-East Memorial Hospital, Taipei County, Taiwan, ROC

${ }^{c}$ Department of Internal Medicine, Lo-Tung Poh-Ai Hospital, I-Lan County, Taiwan, ROC

dInstitute of Epidemiology, College of Public Health, National Taiwan University, Taipei City, Taiwan, ROC

Received 12 November 2003; accepted 27 May 2004

Available online 12 January 2005

\section{KEYWORDS}

Hospital-acquired infection; Length of hospital stay; Medical cost; Mortality

\begin{abstract}
Summary To understand the impact of hospital-acquired infections on mortality and medical costs in modern medical care systems in different healthcare settings, we performed a case-control study at a medical centre and two community hospitals. A total of 144 and 129 adult case-control pairs who received care in a 2000-bed tertiary referral medical centre and two 800 bed community hospitals, respectively, between October 2002 and December 2002 were enrolled. Prolongation of hospital stay, extra costs and complications associated with hospital-acquired infections were analysed. Patients in the medical centre had more severe underlying disease status $(P<0.001)$, more malignancies $(P<0.001)$, more multiple episodes of hospital-acquired infection $(P=0.03)$, and more infections with multidrugresistant bacteria $(P<0.001)$ than patients in community hospitals. The additional length of hospital stay and extra costs were similar for patients with hospital-acquired infections in the community hospitals and the medical centre (mean 19.2 days vs. 20.1 days, $P=0.79$; mean US\$ 5335 vs. US\$ 5058, $P=0.83$; respectively). The additional length of hospital stay and extra costs in both the medical centre and the community hospitals were not related to the sites of infection or the bacterial pathogens causing hospital-acquired infections, although medical costs attributable to hospital-acquired fungal infections due to Candida spp. were much higher for patients in the medical centre. Prevalence of hospital-acquired-infection-related complications, such as adult respiratory distress syndrome, disseminated intravascular coagulation, organ failure or shock, was similar between the two groups, but
\end{abstract}

\footnotetext{
*Corresponding author. Address: Section of Infectious Diseases, Department of Internal Medicine, National Taiwan University Hospital, 7 Chung-Shan South Road, Taipei, Taiwan, ROC. Tel.: +886-2-23123456x5401; fax: +886-2-23971412.
}

E-mail address: sc4030@ha.mc.ntu.edu.tw 
patients in the medical centre had a higher mortality rate because of their underlying co-morbidities.

(C) 2004 The Hospital Infection Society. Published by Elsevier Ltd. All rights reserved.

\section{Introduction}

Hospital-acquired infections are associated with increased attributable mortality, length of hospital stay and costs. ${ }^{1-3}$ Incremental costs of hospitalacquired infections are important to both clinicians and healthcare managers. ${ }^{4,5}$ Although estimates of the cost and prolongation of hospital stay attributable to hospital-acquired infections have been reported, differences in methods used and patients selected for study make comparisons of the estimates difficult. Furthermore, data on hospital costs are generally derived from large, urban, tertiary-care teaching centres. Studies on the economic and clinical impacts of hospital-acquired infections in community hospitals and comparative cost analysis of hospital-acquired infections between community hospitals and tertiary medical centres are lacking. ${ }^{6}$

The literature suggests that community hospitals have lower rates of hospital-acquired infections and serve patients with lesser disease severity than medical centres. Academic tertiary-care centres traditionally serve more immunocompromised individuals, and perform more invasive procedures and aggressive treatments. These variations in processes of care may lead to different characteristics of hospital-acquired infections and pathogens, and affect the choice of antibiotics for empirical therapy. The majority of inpatient care occurs in community hospitals rather than in tertiary-care medical centres. Limited information is available regarding the clinical and economic impacts of hospital-acquired infections in these two different types of hospital. In Taiwan, there is a hospital accreditation system to classify hospitals as medical centres or community hospitals. The community hospitals are further classified as regional or local hospitals. Medical centres have a larger bed capacity (usually more than 800 beds) and better facilities and personnel to provide a wide range of medical services and provide tertiary referral care for patients from community hospitals. Community hospitals have a smaller bed capacity and usually provide primary care for residents in the nearby communities.

The aim of this study was to evaluate the epidemiology, additional length of stay, incremental costs and outcomes due to hospital-acquired infections, and to estimate the potential impact of infection control on community hospitals and medical centres. We also evaluated the sites of infection and the causative pathogens to further assess the impact of hospital-acquired infections in community hospitals and medical centres.

\section{Materials and methods}

\section{Hospital setting and patient selection}

The study was performed in a 2000-bed medical centre (National Taiwan University Hospital, Taipei City) and two 800-bed suburban community hospitals (Lo-Tung Poh-Ai Hospital, I-Lan County and FarEast Memorial Hospital, Taipei County) located in northern Taiwan. Specially trained infection control nurses performed hospital-wide active surveillance of hospital-acquired infections through review of medical records and laboratory data to identify patients with hospital-acquired infections. All hospitalized patients aged $\geq 16$ years with hospital-acquired infections between 1 October 2002 and 31 December 2002 were enrolled. If patients had more than one episode of hospitalacquired infection, data from all episodes were included. Patients were followed and data were collected until death or discharge from the hospital.

Each adult patient who developed hospitalacquired infection (case) identified from the infection control surveillance data was matched to a patient without hospital-acquired infection (controls). Cases were matched by age ( \pm 2 years), sex, underlying medical illness and surgical operation, clinical diagnosis at admission, admission date ( \pm 28 days), ward and disease severity. When several potential controls were found, the control with the nearest age and date of admission to the case was selected. A standardized case record form was used to retrieve clinical and demographic data of cases and controls, hospital costs for diagnostic and therapeutic services, length of stay, complications and final outcomes.

The sites and causative pathogens of hospitalacquired infections of each patient were reviewed by the infectious disease specialists (WHS, JTW and DCTL). Patients with hospital-acquired infections 
but without an identified micro-organism were also reviewed by the infectious disease specialists and recruited into this study. Culture of specimens was performed at the clinical microbiology laboratory in each hospital, and bacteria were identified using conventional methods, VITEK system and/or API system. Antimicrobial susceptibility was determined using the Kirby-Bauer disk diffusion technique, as described by the National Committee for Clinical Laboratory Standards. ${ }^{7}$

Each case was compared with their matched control for the length of hospital stay and costs of hospitalization. In Taiwan, health insurance covers government charges of US\$ 170 and US\$ 150 per day of intensive care unit (ICU) stay and US\$ 30 and US\$ 25 per day of general ward stay in medical centres and community hospitals, respectively. The charges for nursing care, physician rounds, procedures and operations in community hospitals are $85-90 \%$ of the costs in medical centres, and charges for laboratory procedures, drugs and materials are equal. Data on hospitalization costs were retrieved from the central financial service at each hospital, and included information on the total cost of each hospital stay, as well as costs of accommodation, medication, laboratory procedures, materials and services, including catheters, implants, procedures and operations, rehabilitation programmes, respiratory care, dialysis and other special services, physician care, nursing care, consultations and diet.

We also evaluated whether different sites of infection and causative pathogens affected the additional hospital stay and extra cost of hospitalacquired infections. We analysed the data of patients with hospital-acquired respiratory tract infections, urinary tract infections, bloodstream infections and surgical-site infections in each hospital. Also, patients with hospital-acquired infections due to the four most common hospitalacquired pathogens, Staphylococcus aureus, Escherichia coli, Pseudomonas aeruginosa and Candida albicans, were compared to assess the duration of hospital stay and costs.

\section{Definitions}

Hospital-acquired infection was diagnosed according to the definitions of the US Centers for Disease Control and Prevention ${ }^{8}$ when an infection occurred at least $48 \mathrm{~h}$ after hospital admission or within one week of discharge with evidence of infection related to previous hospitalization. Bloodstream infection was defined as positive blood cultures obtained in the presence of fever $\left(\geq 38^{\circ} \mathrm{C}\right)$ that were not attributable to other causes (primary bloodstream infections). Severity of underlying disease was classified using the modified risk stratification proposed by Kreger et al. ${ }^{9}$ as rapidly fatal (death expected within 1 year), ultimately fatal (death expected within 5 years) or non-fatal (death expected in more than 5 years or no underlying disease). Corticosteroid use was defined as receipt of systemic steroids (the equivalent of more than $15 \mathrm{mg}$ /day of prednisolone). Sepsis was defined using the criteria of the American College of Chest Physicians/Society of Critical Care Medicine Consensus Conference. ${ }^{10}$ Respiratory failure was defined as the development of hypoxia necessitating mechanical ventilation, and renal failure was defined as the need for dialysis. The definition of hepatic failure was the presence of jaundice, prolonged prothrombin time, and hepatic encephalopathy. Heart failure was defined as the deterioration of cardiac function necessitating administration of inotropic agents for life support, and neurological failure was defined as the development of coma. The definition of multidrug resistance was when antimicrobial susceptibility tests showed resistance of the isolate to three or more classes of antimicrobial agents.

\section{Statistical analyses}

Analyses of demographics, length of hospital stay and costs were calculated per patient pair with or without hospital-acquired infection during the study period. Analysis of the prolonged hospital stay and cost contribution of different infection sites (respiratory tract, urinary tract, blood and surgical site) and different pathogens (S. aureus, $E$. coli, P. aeruginosa and C. albicans) included only those patient pairs with a single infection site and a single causative pathogen. All statistical analyses were performed using SAS statistical software (Version 8.1, SAS Institute Inc., Cary, NC, USA). Categorical variables, such as demographics and outcomes, were compared using $\chi^{2}$ or Fisher's exact test. Wilcoxon signed rank test (non-parametric methods) was used to compare the difference in length of stay and cost between matched patients with and without hospital-acquired infection. All tests were two-tailed and a $P$ value $<0.05$ was considered to be significant.

\section{Results}

\section{Demographic characteristics of the study population}

During the three-month period, 144 and 129 
matched pairs from the medical centre and the community hospitals, respectively, were recruited for analysis. The demographic characteristics are shown in Table I. The community hospitals contained more elderly (mean age, 71.9 vs. 62.9) and female patients than the medical centre; however, neither reached statistical significance $(P=0.81$ and 0.2 , respectively). Patients recruited from the medical centre had more severe underlying disease than patients from the community hospitals, with $21 \%$ vs. $2 \%$ rapidly fatal diseases and $40 \%$ vs. $22 \%$ ultimately fatal diseases (both $P<0.001$ ). Patients in the medical centre had a higher ratio of underlying medical illness $(89 \%$ vs. $67 \%$, $P<0.001)$, a higher percentage of malignancies (46\% vs. 6\%, $P<0.001$ ) and a higher percentage of recent operation (40\% vs. $29 \%, P=0.05)$ than patients in the community hospitals. There were no differences for other chronic medical illnesses, such as diabetes, chronic heart disease, lung disease, stroke, liver disease and renal disease, and use of steroids between patients recruited from the medical centre and the community hospitals.

\section{Clinical and microbiological characteristics of hospital-acquired infections}

Patients in the medical centre tended to have more multiple episodes of hospital-acquired infection (17\% vs. $9 \%, P=0.03$ ) (Table II), a higher rate of bloodstream infection ( $31 \%$ vs. $13 \%, P<0.001$ ) and a lower rate of respiratory tract infection (14\% vs. $29 \%, P<0.001$ ) compared with patients in the community hospitals. Among the common causative pathogens of hospital-acquired infection, there was no difference between the medical centre and the community hospitals except that patients in the medical centre had more episodes of hospitalacquired infection caused by Enterobacter spp. (14\% vs. $3 \%, P<0.001)$ and anaerobes (3\% vs. $0 \%$, $P=0.04)$ and less episodes caused by Klebsiella spp. (3\% vs. $9 \%, P=0.01$ ) and Serratia spp. (0.7\% vs. $4 \%, P=0.03$ ) than patients in the community hospitals. Patients in the medical centre also had more hospital-acquired infections caused by Candida spp. (15\% vs. $6 \%, P=0.003)$. Sixty-two percent of causative bacteria in the medical centre and $40 \%$ in the community hospitals were multidrug resistant $(P<0.001)$, especially Gram-negative bacilli (71\% vs. $34 \%, P<0.001)$.

\section{Prolonged hospital stay and extra hospital costs}

Cases in the medical centre and the community hospitals had a longer duration of hospital stay and higher costs than controls (Table III). The average increased length of hospital stay for patients with hospital-acquired infections in the medical centre and the community hospitals was 19.2 days and 20.1 days, respectively, including additional stay in the ICU (5.0 days and 8.2 days, respectively) and in the general ward (14.2 days and 11.9 days, respectively). The mean total costs of hospitalization for patients with hospital-acquired infections in the medical centre and the community hospitals were US\$ 13426 and US\$ 8014, respectively, compared with US\$ 8092 and US\$ 2955 for controls. Therefore, patients with hospital-acquired infections had extra costs of US\$ 5335 and US\$ 5058 compared with their matched controls in the medical centre and the community hospitals, respectively. In the subcategories of costs, all types of medical costs were significantly higher in cases than in controls in both healthcare settings.

Patients with hospital-acquired infections in the medical centre had a longer hospital stay $(P=0.02)$ and higher costs $(P<0.001)$ than patients in the community hospitals. Although they had a shorter duration of intensive care (6.7 days vs. 9.7 days; $P=0.09$ ), they had a significantly longer general ward stay than patients in the community hospitals (36.3 days vs. 26.2 days; $P<0.001$ ). All types of medical costs (except diet) were higher for patients in the medical centre than in the community hospitals (Table III), and most differences were statistically significant. However, there were no differences in increased length of stay and extra costs between the medical centre and the community hospitals, except that patients in the community hospitals had a greater increase in the length of ICU stay than patients in the medical centre $(8.2$ days vs. 5.0 days; $P=0.04$ ).

Patients with any type of causative pathogen and any site of hospital-acquired infection had a significantly longer hospital stay than controls in both types of hospital (all $P<0.001$ ) (data not shown), and the increased length of hospitalization was similar (Table IV). There were no differences in extra hospital costs for different sites of infection or causative pathogens, with the exception that patients with hospital-acquired infections due to $C$. albicans in the medical centre had a significantly higher extra cost than patients in the community hospitals (mean, US\$ 6490; $P<0.001$ ). Although the extra costs of patients with surgical-site infections in the medical centre (mean, US\$ 1989) and patients with hospital-acquired infections caused by $P$. aeruginosa in the community hospitals were higher (mean, US\$2427), this did not reach statistical significance. 
Table I Demographic characteristics of 144 patient pairs from the medical centre and 129 patient pairs from the community hospitals

\begin{tabular}{|c|c|c|c|c|c|}
\hline \multirow[t]{2}{*}{ Characteristic } & \multicolumn{2}{|c|}{ Medical centre } & \multicolumn{2}{|c|}{ Community hospitals } & \multirow[t]{2}{*}{$P$ value } \\
\hline & Patients with $\mathrm{HAl}(N=144)$ & Patients without $\mathrm{HAI}(\mathrm{N}=144)$ & Patients without $\mathrm{HAI}(N=129)$ & Patients with $\mathrm{HAl}(N=129)$ & \\
\hline Mean age, SD (range) & $62.9,19.6(16-95)$ & $61.7,17.4(17-93)$ & $71.9,17.4(18-92)$ & $72.4,18.6(19-90)$ & 0.81 \\
\hline \multicolumn{6}{|l|}{ Disease severity } \\
\hline Rapidly fatal (\%) & $30(21)$ & $30(21)$ & $3(2)$ & $3(2)$ & $<0.001$ \\
\hline Ultimately fatal (\%) & $58(40)$ & $58(40)$ & $28(22)$ & $28(22)$ & $<0.001$ \\
\hline Non-fatal (\%) & $56(39)$ & $56(39)$ & $97(75)$ & $97(75)$ & $<0.001$ \\
\hline Underlying medical illness (\%) & $128(89)$ & $128(89)$ & $86(67)$ & $86(67)$ & $<0.001$ \\
\hline Malignancy (\%) & $92(46)$ & $92(46)$ & $8(6)$ & $8(6)$ & $<0.001$ \\
\hline Solid tumours (\%) & $55(38)$ & $55(38)$ & $8(6)$ & $8(6)$ & $<0.001$ \\
\hline Leukaemia (\%) & $37(8)$ & $37(8)$ & $0(0)$ & $0(0)$ & 0.007 \\
\hline Chronic heart disease (\%) & $58(40)$ & $58(40)$ & $59(46)$ & $59(46)$ & 0.36 \\
\hline Diabetes mellitus (\%) & $43(30)$ & $43(30)$ & $51(40)$ & $51(40)$ & 0.09 \\
\hline Chronic lung disease (\%) & $32(22)$ & $32(22)$ & $38(29)$ & $38(29)$ & 0.17 \\
\hline Chronic renal disease (\%) & $28(19)$ & $28(19)$ & $17(13)$ & $17(13)$ & 0.16 \\
\hline Chronic liver disease (\%) & $24(17)$ & $24(17)$ & $13(10)$ & $13(10)$ & 0.11 \\
\hline Neurological disorders (\%) & $20(14)$ & $20(14)$ & $29(22)$ & $29(22)$ & 0.07 \\
\hline
\end{tabular}

HAl, hospital-acquired infection; SD, standard deviation.

a value: comparison of the characteristics of patients with $\mathrm{HAl}$ in the medical centre and in the community hospitals. 


\begin{tabular}{|c|c|c|c|}
\hline & Medical centre & Community hospital & $P$ value \\
\hline Episode number of patients with HAI & $N=144$ & $N=129$ & \\
\hline Single episode & $119(83 \%)$ & $118(91 \%)$ & 0.03 \\
\hline Multiple episodes & $25(17 \%)$ & $11(9 \%)$ & 0.03 \\
\hline Two & $20(14 \%)$ & $9(7 \%)$ & 0.06 \\
\hline Three & $3(2 \%)$ & $2(2 \%)$ & 0.74 \\
\hline Four & $2(1 \%)$ & $0(0 \%)$ & 0.18 \\
\hline Sites of HAI & $N=176$ & $N=142$ & \\
\hline Urinary tract & $50(28 \%)$ & $52(37 \%)$ & 0.12 \\
\hline Respiratory tract & $25(14 \%)$ & $41(29 \%)$ & $<0.001$ \\
\hline Bloodstream & $54(31 \%)$ & $19(13 \%)$ & $<0.001$ \\
\hline Surgical site & $26(15 \%)$ & $17(12 \%)$ & 0.47 \\
\hline Others & $21(12 \%)$ & $13(9 \%)$ & 0.43 \\
\hline Aetiological micro-organism & $N=239$ & $N=174$ & \\
\hline Gram-positive bacteria & $53(22 \%)$ & $52(30 \%)$ & 0.08 \\
\hline Staphylococcus aureus & $18(8 \%)$ & $21(12 \%)$ & 0.12 \\
\hline Methicillin-resistant S. aureus & $14(6 \%)$ & $18(10 \%)$ & 0.09 \\
\hline Coagulase-negative Staphylococci & $6(3 \%)$ & $5(3 \%)$ & 0.82 \\
\hline Enterococci & $11(5 \%)$ & $7(4 \%)$ & 0.78 \\
\hline Viridans streptococci & $4(2 \%)$ & $1(0.5 \%)$ & 0.31 \\
\hline Gram-negative bacteria & $144(60 \%)$ & $112(64 \%)$ & 0.39 \\
\hline Escherichia coli & $34(14 \%)$ & $31(18 \%)$ & 0.32 \\
\hline Pseudomonas aeruginosa & 29 (12\%) & $26(15 \%)$ & 0.41 \\
\hline Enterobacter spp. & $33(14 \%)$ & $5(3 \%)$ & $<0.001$ \\
\hline Acinetobacter baumannii & $18(8 \%)$ & $11(6 \%)$ & 0.64 \\
\hline Klebsiella pneumoniae & $7(3 \%)$ & $15(9 \%)$ & 0.01 \\
\hline Morganella movganii & $2(0.7 \%)$ & $2(1 \%)$ & 0.75 \\
\hline Serratia marcescens & $2(0.7 \%)$ & $7(4 \%)$ & 0.03 \\
\hline Proteus mirabilis & $2(0.7 \%)$ & $5(3 \%)$ & 0.11 \\
\hline Others & $17(7 \%)$ & $10(6 \%)$ & 0.58 \\
\hline Anaerobe & $6(3 \%)$ & $0(0 \%)$ & 0.04 \\
\hline Candida spp. & $36(15 \%)$ & $10(6 \%)$ & 0.003 \\
\hline Multidrug-resistant bacteria ${ }^{a}$ ( $\geq$ three classes of antimicrobials) & $136(62 \%)$ & $63(40 \%)$ & $<0.001$ \\
\hline Gram-positive cocci & $31(58 \%)$ & $25(48 \%)$ & 0.29 \\
\hline Gram-negative bacilli & $102(71 \%)$ & $38(34 \%)$ & $<0.001$ \\
\hline
\end{tabular}

HAI, hospital-acquired infection.

${ }^{a}$ Multidrug-resistant bacteria: resistant to three or more classes of antimicrobials by disk diffusion method.

\section{Clinical outcomes}

Hospital-acquired infections were associated with more complications during hospitalization, such as shock, disseminated intravascular coagulation, coma, organ failure (necessitating dialysis and ventilatory support) and multiple organ failure. However, the incidence of these complications due to hospital-acquired infections was similar between the medical centre and the community hospitals (Table V). Patients acquiring hospital-acquired infections in the medical centre underwent more operations for management of these infections than patients in the community hospitals $(P=0.06)$. The crude mortality rates were $29 \%$ for the medical centre and $15 \%$ for the community hospitals ( $P=$ 0.004). Attributable mortality was also higher for patients in the medical centre than in the community hospitals ( $9 \%$ vs. $3 \%, P=0.04$ ). Seven patients with hospital-acquired infections in the medical centre died within three days despite intensive care, but none of the patients in the community hospital died within this period. Patients with rapidly fatal hospital-acquired infections had a shorter hospital stay and lower costs than their matched controls because of early mortality due to severe sepsis.

\section{Discussion}

Changes in the pattern of healthcare delivery and resource utilization have significantly affected decision making for both government and hospital 
Table III Hospital stay and costs for patients with or without hospital-acquired infections

\begin{tabular}{|c|c|c|c|c|c|c|c|c|c|c|}
\hline \multirow[t]{2}{*}{ Category } & \multicolumn{4}{|c|}{ Medical centre $(N=144)$} & \multicolumn{4}{|c|}{ Community hospital $(N=129)$} & \multirow[t]{2}{*}{ P3 value ${ }^{a}$} & \multirow[t]{2}{*}{ P4 value } \\
\hline & $\begin{array}{l}\text { With HAI cases } \\
\text { Mean (SD) }\end{array}$ & $\begin{array}{l}\text { Without HAI controls } \\
\text { Mean (SD) }\end{array}$ & $\begin{array}{l}\text { Increased LOS } \\
\text { and extra costs } \\
\text { Mean (SD) }\end{array}$ & $P 1$ value $^{c}$ & $\begin{array}{l}\text { With HAl cases } \\
\text { Mean (SD) }\end{array}$ & $\begin{array}{c}\text { Without HAI controls } \\
\text { Mean (SD) }\end{array}$ & $\begin{array}{l}\text { Increased LOS } \\
\text { and extra costs } \\
\text { Mean (SD) }\end{array}$ & $P 2$ value $^{d}$ & & \\
\hline Total days & $44.0(28.6)$ & $24.8(20.7)$ & $19.2(31.8)$ & $<0.001$ & 36.7 (22.7) & $16.6(11.8)$ & $20.1(22.8)$ & $<0.001$ & 0.02 & 0.79 \\
\hline ICU & $6.7(14.1)$ & $1.7(5.1)$ & $5.0(10.9)$ & $<0.001$ & $9.7(14.9)$ & $1.5(4.4)$ & $8.2(14.4)$ & $<0.001$ & 0.09 & 0.04 \\
\hline Wards & $36.3(28.8)$ & $22.5(20.7)$ & $14.2(31.4)$ & $<0.001$ & $26.2(20.1)$ & $14.3(12.0)$ & $11.9(20.9)$ & $<0.001$ & $<0.001$ & 0.46 \\
\hline Total charges & $13426(11796)$ & 8092 (10283) & 5335 (13872) & $<0.001$ & 8014 (7238) & 2955 (3255) & 5058 (5885) & $<0.001$ & $<0.001$ & 0.83 \\
\hline Pharmacy & $4948(5266)$ & 3265 (5617) & 1682 (6964) & $<0.001$ & $1782(1807)$ & 578 (982) & 1204 (1513) & $<0.001$ & $<0.001$ & 0.42 \\
\hline Laboratory & 1493 (1099) & 988 (1865) & 505 (2088) & $<0.001$ & $868(1053)$ & $355(504)$ & $513(812)$ & $<0.001$ & $<0.001$ & 0.97 \\
\hline Accommodation & $2627(2540)$ & 1091 (1877) & $1536(3108)$ & $<0.001$ & 2096 (1994) & 761 (967) & $1335(1626)$ & $<0.001$ & 0.06 & 0.50 \\
\hline Materials and services & 4119 (3991) & $2723(3888)$ & 1396 (4591) & $<0.001$ & $3076(238)$ & 1164 (207) & $1912(246)$ & $<0.001$ & 0.02 & 0.26 \\
\hline Diet & $240(978)$ & $25(77)$ & $215(944)$ & $<0.001$ & $192(238)$ & 97 (207) & $94(246)$ & $<0.001$ & 0.57 & 0.14 \\
\hline
\end{tabular}

ICU, intensive care unit; LOS, length of stay; HAI, hospital-acquired infection; SD, standard deviation. 1 US dollar (US\$) = 34 New Taiwan Dollars (NT\$s).

a $P 3$ value: comparison of LOS and costs between patients with HAI in the medical centre and those in the community hospitals.

b P4 value: comparison of prolonged LOS and extra costs between patients with and without HAI (patient pairs) in the medical centre and the community hospitals.

c $P 1$ value: comparison of LOS and costs between patients with and without HAI in the medical centre.

${ }^{d} P 2$ value: comparison of LOS and costs between patients with and without HAI in the community hospitals.

Table IV Comparison of prolonged stay and extra hospital costs between different pathogens and infection sites

\begin{tabular}{|c|c|c|c|c|c|c|c|c|}
\hline & \multicolumn{4}{|c|}{ Prolonged stay } & \multicolumn{4}{|c|}{ Extra hospital costs } \\
\hline & $\begin{array}{l}\text { Medical centre } \\
\text { Mean (SD) }\end{array}$ & $\begin{array}{l}\text { Community hospital } \\
\text { Mean (SD) }\end{array}$ & $\begin{array}{l}\text { Difference } \\
\text { Mean (SD) }\end{array}$ & $P$ value & $\begin{array}{l}\text { Medical centre } \\
\text { Mean (SD) }\end{array}$ & $\begin{array}{c}\text { Community hospital } \\
\text { Mean (SD) }\end{array}$ & $\begin{array}{l}\text { Difference } \\
\text { Mean (SD) }\end{array}$ & $P$ value \\
\hline Total & $19.2(31.8)$ & $20.1(22.8)$ & $-0.89(27.9)$ & 0.79 & 5335 (13872) & $5058(5885)$ & 277 (10858) & 0.83 \\
\hline \multicolumn{9}{|l|}{ Sites of $\mathrm{HAl}^{\mathrm{a}}$} \\
\hline Urinary tract & $17.5(32.7)$ & $20.7(28.2)$ & $-3.2(16.5)$ & 0.81 & 3725 (11163) & $2832(4620)$ & $894(8580)$ & 0.09 \\
\hline Respiratory tract & $18.4(38.1)$ & $21.3(16.3)$ & $-2.9(18.8)$ & 0.39 & $5146(22906)$ & $6078(5963)$ & $-933(14092)$ & 0.53 \\
\hline Blood & $15.5(24.7)$ & $16.6(17.4)$ & $-1.1(14.2)$ & 0.94 & 4872 (13012) & 4643 (3275) & $229(11270)$ & 0.92 \\
\hline Surgical site & $14.4(25.8)$ & $14.4(9.6)$ & $0.1(13.7)$ & 0.78 & 4471 (9911) & $2482(2552)$ & $1989(7676)$ & 0.07 \\
\hline \multicolumn{9}{|l|}{ Pathogens that caused $\mathrm{HAl}^{\mathrm{a}}$} \\
\hline Staphylococcus aureus & $17.3(29.5)$ & $21(18.4)$ & $-3.7(17.3)$ & 0.82 & 3294 (10401) & 4897 (6702) & $-1603(6395)$ & 0.51 \\
\hline Escherichia coli & $14.3(40.3)$ & $20.2(29.6)$ & $-5.8(33.9)$ & 0.65 & 1354 (10569) & $2250(3467)$ & $-896(6982)$ & 0.88 \\
\hline Pseudomonas aeruginosa & $23.6(37.6)$ & $22.8(11.9)$ & $0.8(25.1)$ & 0.81 & 1202 (17962) & 3629 (5340) & -2427 (11901) & 0.09 \\
\hline Candida albicans & $18.4(28.5)$ & $13.7(41.0)$ & $4.72(29.7)$ & 0.60 & 6584 (11467) & $93(1050)$ & $6490(10983)$ & $<0.001$ \\
\hline
\end{tabular}

HAI, hospital-acquired infection; SD, standard deviation.

a Analysis was performed of patients with a single-site HAI or a single causative pathogen. 
administrators and physicians. ${ }^{11-13}$ Most community hospitals provide modern medical care including coronary catheterization and chemotherapy for patients with autoimmune diseases and malignancy. Our study from a tertiary referral medical centre and two community hospitals shows that patients in community hospitals have less severe underlying diseases and malignancy than patients in medical centres. However, they had the same prolongation of hospital stay (20 extra days) and similar extra costs (about US\$ 5000) for each patient with hospital-acquired infection. The incidence of hospital-acquired-infection-related complications, such as adult respiratory distress syndrome, disseminated intravascular coagulation, organ failure or shock, was similar in both healthcare settings. Thus, hospital-acquired infections in community hospitals pose an enormous expense.

Case-control studies matching multiple variables associated with length of stay and cost analysis are commonly used to study the impact of hospitalacquired infections. ${ }^{11-15}$ In this study, cases and controls were comparable in demographic and other characteristics, and the control patients were selected from all patients admitted to the same hospital during the same time period; they were matched by primary discharge diagnosis, operative procedure, disease severity and age. The medical centre had more patients with malignancies and severe underlying illnesses that required multiple invasive procedures and immunosuppressive chemotherapy, and the higher rate of multiple episodes of hospital-acquired infections and bloodstream infections is not unexpected. Community hospitals had more elderly patients with neurological diseases (mostly strokes) and diabetes, which may partially explain why these patients had more hospital-acquired pneumonia.

Resistance of hospital-acquired pathogens to multiple antimicrobial agents has become a major problem in the management of hospital-acquired infections. Patients in the medical centre and the community hospitals had a high rate of multidrugresistant bacterial infections $(62 \%$ and $40 \%$, respectively). Duration of hospital stay and costs of hospital-acquired infections are significantly higher in patients infected with resistant bacteria. ${ }^{16-20}$ Patients with resistant bacterial hospital-acquired infections consume more hospital resources and have a poorer outcome. Hospitalacquired infections caused by multidrug-resistant bacteria and fungi were more common in the medical centre, partly due to their complicated hospital courses and increased usage of broadspectrum antibacterial agents for previous infections.

Direct (or marginal) costs of hospitalization have been proposed as a better method for estimating the costs of hospital-acquired infections than total costs or patient charges. ${ }^{11}$ However, the extra costs and additional hospital stay found in the present study may be an underestimate because some patients with hospital-acquired infections died rapidly, resulting in lower costs and shorter duration of hospitalization. Furthermore, our data only reflect the costs for medical care; the costs of illness in terms of loss of productivity, loss of income, and social burden for diseased patients were not considered.

Previous case-control studies have clearly demonstrated that hospital-acquired infections prolong hospitalization significantly, ${ }^{13,21,22}$ and

Table V Comparison of complications due to hospital-acquired infections and outcomes between the medical centre and the community hospitals

\begin{tabular}{|c|c|c|c|c|c|c|c|}
\hline \multirow[b]{2}{*}{ Complications } & \multicolumn{2}{|c|}{$\begin{array}{l}\text { Medical centre } \\
\quad(N=144)\end{array}$} & \multicolumn{2}{|c|}{$\begin{array}{l}\text { Community hospital } \\
\qquad(N=129)\end{array}$} & \multicolumn{3}{|c|}{$\begin{array}{c}\text { Differences of complications } \\
\text { due to HAl }\end{array}$} \\
\hline & $\begin{array}{l}\text { With HAl } \\
\text { (cases) }\end{array}$ & $\begin{array}{l}\text { Without HAI } \\
\text { (controls) }\end{array}$ & $\begin{array}{l}\text { With HAI } \\
\text { (cases) }\end{array}$ & $\begin{array}{l}\text { Without HAI } \\
\text { (controls) }\end{array}$ & Medical centre & Community hospital & $P$ value \\
\hline Shock & 17 & 5 & 7 & 0 & $12(8 \%)$ & $7(5 \%)$ & 0.35 \\
\hline DIC & 4 & 0 & 1 & 0 & $4(3 \%)$ & $1(<1 \%)$ & 0.22 \\
\hline Respiratory failure & 11 & 2 & 5 & 1 & $9(6 \%)$ & $4(3 \%)$ & 0.22 \\
\hline Renal failure & 10 & 4 & 3 & 1 & $6(4 \%)$ & $2(2 \%)$ & 0.20 \\
\hline Neurological failure & 9 & 5 & 2 & 0 & $4(3 \%)$ & $2(2 \%)$ & 0.49 \\
\hline Hepatic failure & 5 & 2 & 1 & 0 & $3(2 \%)$ & $1(<1 \%)$ & 0.37 \\
\hline Heart failure & 5 & 4 & 0 & 0 & $1(<1 \%)$ & $0(0 \%)$ & 0.34 \\
\hline MOFS & 10 & 3 & 3 & 0 & $7(5 \%)$ & $3(2 \%)$ & 0.27 \\
\hline Operation for HAI & 4 & 0 & 0 & 0 & $4(3 \%)$ & $0(0 \%)$ & 0.06 \\
\hline Death & 52 & 10 & 19 & 0 & $42(29 \%)$ & $19(15 \%)$ & 0.004 \\
\hline Death due to HAI & 13 & 0 & 4 & 0 & $13(9 \%)$ & $4(3 \%)$ & 0.04 \\
\hline
\end{tabular}

DIC, disseminated intravascular coagulation; MOFS, multiple organ failure syndrome; HAI, hospital-acquired infection. 
suggested that accommodation costs account for more than half (even up to $90 \%$ ) of the total additional charges. ${ }^{15,23-25}$ Most studies have used the length of hospitalization as an indicator of resource utilization attributable to hospitalacquired infections. ${ }^{13,21,22,26-28}$ The contribution of the costs related to laboratory investigations, pharmacy, materials, operations and diet are rarely discussed. In this study, the costs of materials, operations, physician fees and drugs were much higher than accommodation costs. Therefore, extra charges attributed solely to prolonged hospital stay are likely to underestimate the total costs. The impact of hospital-acquired infections on various components of hospital costs should be emphasized.

Some studies have shown that the cost of hospital-acquired infections may depend on the site of infection. ${ }^{29-33}$ The present study investigated whether the site of infection and the causative organism might have an impact on prolonged hospital stay and extra costs. We found that patients with hospital-acquired respiratory tract infections had higher costs and longer hospital stays, although this difference did not reach statistical significance. Hospital-acquired fungal infections had higher costs than bacterial infections, partly due to their complicated hospital course and partly due to the fact that superinfection with fungi usually developed after the use of broad-spectrum antibacterial agents for previous bacterial infections. We did not find any differences among various species of bacteria in incurring extra hospital costs.

The majority of inpatient care occurs in community hospitals $(66 \%)$ rather than in tertiary-care medical centres in Taiwan. The need for effective infection control programmes within community hospitals and adequate monitoring should be emphasized.

Hospital-acquired infections have a significant impact on the length of additional hospital stay and extra costs in both medical centres and community hospitals. ${ }^{34}$ Although patients in community hospitals have lesser disease severity and the infections do not contribute to the same mortality rate as in patients in medical centres, hospital-acquired infections result in increased suffering and costs for patients with prolonged hospital stays and more life-threatening complications. This study found that the extra costs of hospital-acquired infections were not only due to prolongation of hospital stay, but also due to other medical costs. The outcome of patients with hospital-acquired infections was significantly worse than that of their matched controls, and the results were similar for patients in medical centres and in community hospitals.

\section{References}

1. Mahieu LM, Buitenweg N, Beutels P, De Dooy JJ. Additional hospital stay and charges due to hospital-acquired infections in a neonatal intensive care unit. J Hosp Infect 2001;47: 223-229.

2. McGowan Jr. JE. Cost and benefit-a critical issue for hospital infection control. Fifth Annual National Foundation for Infectious Diseases Lecture. Am J Infect Control 1982; 10:100-108.

3. Jarvis WR. Selected aspects of the socioeconomic impact of nosocomial infections: morbidity, mortality, cost and prevention. Infect Control Hosp Epidemiol 1996;17:552-557.

4. Wenzel RP. Nosocomial infections, diagnosis-related groups, and study on the efficacy of nosocomial infection control. Economic implications for hospitals under the prospective payment system. Am J Med 1985;78:S3-S7.

5. Wenzel RP. The economics of nosocomial infections. J Hosp Infect 1995;31:79-87.

6. Warren DK, Zack JE, Elward AM, Cox MJ, Fraser VJ. Nosocomial primary bloodstream infections in intensive care unit patients in a nonteaching community medica center-a 21 month prospective study. Clin Infect Dis 2001; 33:1329-1335.

7. National Committee for Clinical Laboratory Standards, Methods for dilution antimicrobial susceptibility tests for bacteria that grow aerobically., Approved standard M7-A4. Wayne, Pennsylvania: NCCLS; 2001.

8. Garner JS, Jarvis WR, Emori TG, et al. CDC definitions for nosocomial infections. Am J Infect Control 1988;16: $128-140$.

9. Kreger BE, Craven DE, McCabe WR. Gram-negative bacteremia. Am J Med 1980;68:344-355.

10. Bone RC, Balk RA, Cerra FB, et al. Definitions for sepsis and organ failure and guidelines for the use of innovative therapies in sepsis. The ACCP/SCCM Consensus Conference Committee. American College of Chest Physicians/Society of Critical Care Medicine. Chest 1992;101:1644-1655.

11. Haley RW. Measuring the costs of nosocomial infections: methods for estimating economic burden on the hospital. Am J Med 1991;91:S32-S38.

12. Freeman J, McGowan Jr. JE. Methodologic issues in hospital epidemiology-investigating the modifying effects of time and severity of underlying illness on estimates of cost of nosocomial infection. Rev Infect Dis 1984;6:285-300.

13. Haley RW, Schaberg DR, von Allmen SD, McGowan Jr. JE. Estimating the extra charges and prolongation of hospitalization due to nosocomial infections: a comparison of methods. J Infect Dis 1980;141:248-257.

14. Haley RW, Schaberg DR, Crossley KB, von Allmen SD, McGowan Jr. JE. Extra charges and prolongation of stay attributable to nosocomial infections: a prospective interhospital comparison. Am J Med 1981;70:51-58.

15. Wakefield DS, Helms CM, Massanari RM, Mori M, Pfaller M. Cost of nosocomial infection: relative contributions of laboratory, antibiotic, and per diem costs in serious Staphylococcus aureus infections. Am J Infect Control 1988;16:185-192.

16. Kim T, Oh PI, Simor AE. The economic impact of methicillinresistant Staphylococcus aureus in Canadian hospitals. Infect Control Hosp Epidemiol 2001;22:99-104. 
17. Carmeli Y, Troillet N, Karchmer AW, Samore MH. Health and economic outcomes of antibiotic resistance in Pseudomonas aeruginosa. Arch Intern Med 1999;159:1127-1132.

18. Kremery Jr. V, Spanik S, Krupova I, et al. Bacteremia due to multi-resistant Gram-negative bacilli in neutropenic cancer patients-a case controlled study. J Chemother 1998;10: 320-325.

19. Chow JW, Fine MJ, Shlaes DM, et al. Enterobacter bacteremia-clinical features and emergence of antibiotic resistance during therapy. Ann Intern Med 1991;115: 585-590.

20. Abramson MA, Sexton DJ. Nosocomial methicillin-resistant and methicillin-susceptible Staphylococcus aureus primary bacteremia-at what costs? Infect Control Hosp Epidemiol 1999;20:408-411.

21. Freeman J, Rosner BA, McGowan Jr. JE. Adverse effects of nosocomial infections. J Infect Dis 1979;140:732-740.

22. Green MS, Rubinstein E, Amit P. Estimating the effects of nosocomial infections on the length of hospitalization. $J$ Infect Dis 1982;145:667-672.

23. Leroyer A, Bedu A, Lombrail P, et al. Prolongation of hospital stay and extra cost due to hospital-acquired infection in a neonatal unit. J Hosp Infect 1997;35:37-45.

24. Vegas AA, Jodra VM, Garcia ML. Nosocomial infection in surgery wards: a controlled study of increased duration of hospital stays and direct cost of hospitalization. Eur $J$ Epidemiol 1993;9:504-510.

25. Coello R, Glenister H, Fereres J, et al. The cost of infection in surgical patients: a case-control study. J Hosp Infect 1993; 25:239-250.

26. Dietrich ES, Demmler M, Schulgen G, et al. Nosocomial pneumonia: a cost-of-illness analysis. Infection 2002;30: 61-67.

27. Cruse PJE, Ford R. The epidemiology of wound infections: a 10 -year prospective study of 62,939 wounds. Surg Clin North Am 1980;60:27-40.

28. Green JW, Wenzel RP. Post-operative wound infections: a controlled study of hospitalization. Ann Surg 1977;185: 264-268.

29. Scheckler WE. Hospital costs of nosocomial infections: a prospective three-month study in a community hospital. Infect Control 1980;1:150-152.

30. Spengler RF, Greenough WB. Hospital costs and mortality attributed to nosocomial bacteremia. JAMA 1978;240: 2455-2458.

31. Kirkland KB, Briggs JP, Trivette SL, Wilkinson WE, Sexton DJ. The impact of surgical-site infections in the 1990s: attributable mortality, excess length of hospitalization, and extra costs. Infect Control Hosp Epidemiol 1999;20:725-730.

32. Rubinstein E, Green M, Modan M, Amit P, Bernstein L, Rubinstein A. The effects of nosocomial infections on the length and costs of hospital stay. J Antimicrob Chemother 1982;9:S93-S100.

33. Orsi GB, Stefano LD, Noah N. Hospital-acquired, laboratoryconfirmed bloodstream infection-increased hospital stay and direct costs. Infect Control Hosp Epidemiol 2002;23: 190-197.

34. Whitehouse JD, Friedman ND, Kirkland KB, Richardson WJ, Sexton DJ. The impact of surgical site infections following orthopedic surgery at a community hospital and a university hospital-adverse quality of life, excess length of stay, and extra cost. Infect Control Hosp Epidemiol 2002;23:183-189. 